\title{
PROCESO (¿)CONSTITUYENTE(?)
}

\section{Constituent(?) Process}

\author{
Pablo Contreras* \\ Domingo Lovera ${ }^{* *}$ \\ Ernesto Riffo ${ }^{* * *}$
}

Resumen: El presente trabajo analiza el itinerario de cambio constitucional propuesto por la Presidenta Michelle Bachelet. Junto con una descripción del mismo, se discuten, críticamente, varias de sus etapas. En lo principal, se objeta el conjunto de cerrojos institucionalmente vigentes que harían imposible, al menos desde una perspectiva teórica, hablar de un proceso genuinamente constituyente. El trabajo ofrece, al mismo tiempo, una lectura democráticamente adecuada para que el proceso permita un diálogo entre la institucionalidad que se pretende abandonar y el mecanismo con el que se busca el cambio constitucional, sin que las primeras limiten al segundo.

Palabras clave: cambio constitucional - proceso constituyente - poder constituyente cerrojos institucionales - Chile.

Abstract: This work analyzes the itinerary for constitutional change that President Michelle Bachelet recently announced. Along with a presentation of the process, this work critically assesses some of its stages. It mainly contends that the set of institutional regulations it assumed-regulations that were taken from current constitutional rules-makes it impossible to talk, at least from a theoretical perspective, of a genuine constituent process. This work also offers a democratically adequate reading for the process, so that it will make possible a dialogue between the current institutions sought to be replaced and the mechanism for constitutional change, without subjecting the latter to the former.

Keywords: constitutional change - constituent process - constituent power - institutional locks - Chile.

\footnotetext{
*Abogado, Ll.M. Northwestern University, Profesor de Derecho Constitucional, Facultad de Derecho, Universidad Alberto Hurtado. Correo electrónico: pacontrı@uahurtado.cl

**A bogado, Ll.M. Columbia University, Profesor asistente, Facultad de Derecho, Universidad Diego Portales. Correo electrónico: domingo.lovera@udp.cl

***A Abogado, Profesor de Derecho, Escuela de Derecho, Universidad Católica Silva Henríquez. Correo electrónico: eriffo@ucsh.cl
}

Este artículo fue recibido el 25 de noviembre de 2015, siendo aprobada su publicación el 14 de diciembre de 2015. 


\section{INTRODUCCIÓN}

El día 13 de octubre de 2015, la Presidenta Michelle Bachelet anunció lo que se ha venido en denominar el itinerario del proceso constituyente. En términos generales, el itinerario es el que sigue. ${ }^{1}$ Este se iniciará con una etapa de pedagogía cívico/constitucional que debiera extenderse entre los meses de noviembre de 2015 y marzo de 2016. Esta primera etapa servirá, afirmó la Presidenta, para proveer a la ciudadanía de la información necesaria ("todas las herramientas necesarias," dispone a información de Gobierno) que le permita, luego, intervenir con una base adecuada de conocimiento para la segunda etapa: la denominada etapa de diálogos ciudadanos. Los diálogos ciudadanos o participativos, desde luego, ya no buscarán únicamente capacitar a la ciudadanía, sino que, en cambio, abrir un sistema de consultas de la comunidad - a nivel comunal, luego provincial, para avanzar a las regiones y terminar "con una síntesis a nivel nacional"-que permita "recoger todas las voces".

¿Cómo se asegurará que estas etapas permitan, como se ha dicho, la realización de un "proceso participativo [que] sea libre, transparente, sin distorsiones ni presiones de ningún tipo"? La respuesta del itinerario es crear un 'Consejo Ciudadano' que se encargará de vigilar la transparencia y equidad de las instancias educativas y participativas, respectivamente. Ese Consejo, cuyos nombres, prometió la Presidenta, serán de reconocido prestigio para "dar fe de la calidad del proceso," será nombrado por el propio Gobierno. El itinerario llama al resultado del trabajo de estas dos primeras etapas de educación y diálogos las 'Bases Ciudadanas para la Nueva Constitución'.

¿Serán las ‘Bases Ciudadanas’ el material sobre el que discutirán la instancia constituyente, cualquiera que sea la forma que esta adopte? La respuesta es clara: no. Dichas 'Bases' serán recogidas por la Presidenta de la República, con las que dará forma a un proyecto de Nueva Constitución. Que no serán esas 'Bases' piedra de toque del proceso constituyente lo evidencia el hecho que ellas serán sometidas a cotejo ("serán transformadas," afirman los documentos que citamos) con "lo mejor de la tradición constitucional chilena y que esté acorde con las obligaciones jurídicas que Chile ha contraído con el mundo". Es decir, la tradición constitucional chilena y las obligaciones que el Estado ha contraído internacionalmente, moldearán las 'Bases Ciudadanas'. Por lo tanto, las 'Bases Ciudadanas' no equivalen al proyecto de Nueva Constitución que elaborará la

\footnotetext{
${ }^{1}$ Nos basamos, para efectos de esta descripción, tanto en el discurso de la Presidenta como en la infografía que el Gobierno de Chile ha puesto a disposición de la ciudadanía. Las citas que se efectúan en esta introducción, al menos que se indique lo contrario, corresponden a dichos documentos (fecha de consulta 19 de noviembre de 2015). Los documentos se encuentran disponibles, respectivamente, en: http://www.gob.cl/2015/10/13/discurso-de-la-presidenta-de-larepublica-al-anunciar-el-proceso-constituyente/ y http://www.gob.cl/2015/10/13/infografiaconoce-las-etapas-del-proceso-constituyente/
} 
Presidenta y que someterá a conocimiento del Congreso Nacional -según se indica-a inicios del segundo semestre de 2017.

¿Con qué objeto? En esto, el itinerario no es claro. Desde el punto de vista político, sin embargo, es evidente: el actual Congreso no procederá a habilitar al siguiente parlamento si no es conociendo, previamente, cuáles son los contenidos de fondo. ${ }^{2}$ Esa es la garantía de fondo -y sobre esto volveremos más abajo-para proceder a concretar lo que la Presidenta llamó el cauce institucional para el proceso. ${ }^{3}$ ¿En qué consiste este cauce? La Presidenta afirmó, acertadamente, que la actual regulación "no contempla mecanismos para elaborar una nueva Carta Fundamental". Por ello, propone una reforma constitucional que permita transitar desde las actuales regulaciones a una nueva Constitución. Al menos de lo que puede deducirse del itinerario, el contenido de esa reforma es bastante concreto: solo debe permitir al actual Congreso habilitar al próximo parlamento para decidir sobre el mecanismo constituyente. El otro aspecto crucial de esta, la que abre el cauce institucional del proceso, es el quórum con que dicha reforma deberá aprobarse. La Presidenta sostuvo que para que dicha habilitación sea posible "dentro de nuestra actual legislación," se necesita el concurso de las $2 / 3$ de los miembros en ejercicio del Congreso.

De lograrse el quórum en comento, se logra habilitar al próximo parlamento para que decida cuál es el mecanismo (constituyente, debería añadirse) conforme al que se procederá a adoptar la Nueva Constitución. El proyecto contempla cuatro posibilidades: (i) una asamblea constituyente; (ii) un congreso constituyente; (iii) una comisión mixta compuesta por ciudadanos, ciudadanas y parlamentarios; $y$, finalmente, (iv) un plebiscito para que sea la ciudadanía la que decida el mecanismo para la Nueva Constitución. Esta decisión debe adoptarse por las $3 / 5$ partes de los miembros en ejercicio del 'nuevo' Congreso.

En lo que sigue, nos proponemos discutir críticamente el itinerario. Y lo haremos a la luz de cuatro de sus aspectos; los cuatro aspectos que, creemos,

\footnotetext{
2 Se habla del próximo parlamento para identificar al Congreso compuesto, casi en su totalidad, por miembros que serán electos y electas a fines de 2017. Esas elecciones tendrán lugar con un nuevo sistema electoral que reduce significativamente las trampas del actual sistema electoral binominal ${ }^{3}$ El senador Hernán Larraín (UDI), por ejemplo, fue claro al respecto: "se nos ha dado garantías de que antes de cambiar el capítulo de la reforma se va a conocer el contenido". "DC y RN reviven diálogos políticos y agendan primera cita por nueva Constitución", La Tercera, 17 de octubre 2015, p. 12.

4 Decimos acertadamente en la medida que las actuales regulaciones constitucionales no contienen un mecanismo de reemplazo total de la Constitución. Cosa distinta, discutiremos más abajo, es si las constituciones contemplan, suelen contemplar o si es necesario que contemplen esos mecanismos.
} 
mayor tratamiento han recibido desde la teoría constitucional. En primer lugar (1), queremos discutir cuál es el papel que desempeñará el denominado proyecto de Nueva Constitución, y cuya elaboración el itinerario reserva a la Presidenta de la República. En lo medular, queremos cuestionar la capacidad de este proyecto -no obstante su utilidad política para lograr los consensos adecuados para satisfacer los $2 / 3$ que el itinerario reclama para esta parte del proceso-para sujetar a las instancias constituyentes en lo que respecta al fondo de su decisión. En segundo lugar, (2) queremos debatir en torno a la idea de 'cauce institucional' para el proceso constituyente. En lo principal, mostraremos que el recurso a la institucionalidad es ineludible en un proceso constituyente. Ello no porque el momento constituyente deba sujetarse a reglas formales o procedimentales, sino porque las necesita para poder decidir y, finalmente, para ser reconocido como una forma de poder (el constituyente) distinto del ordinario o regular (el constituido). Sin embargo, sabemos que el sentido de la 'institucionalidad' a que se refiere el itinerario se aleja, en parte, de la discusión que ofrece la teoría constitucional. Ello es evidente cuando se anota que la Presidenta se refiere al cauce institucional haciéndolo equivalente con "nuestra actual legislación". Precisamente esto es lo que criticamos; (3) proponemos que, de acuerdo a nuestras reglas constitucionales vigentes, no hay ninguna razón para que la habilitación a que se refiere el itinerario deba acordarse por las $2 / 3$ partes de los miembros en ejercicio del Congreso. La última sección de este trabajo (4) sostendremos que el proyecto de Nueva Constitución no puede atar sustantivamente la decisión de la instancia (cualquiera) constituyente y que el Tribunal Constitucional debe resistir la tentación de intentar tal sujeción. Salvo, claro está, que no sea constituyente y que su resultado sea, no otra cosa que, una reforma. $\mathrm{O}$ varias.

\section{Fondo y forma}

Según Fernando Atria, que la forma sea el fondo (o sustancia), significa que es el mecanismo el que hará viable la posibilidad de una Nueva Constitución. En sus palabras, "hay muchas maneras en la que un texto constitucional puede ser escrito. Pero no todas esas maneras son formas de darse una constitución". ${ }^{5}$ Que forma sea fondo significa afirmar, a un tiempo, como hace Atria, que el (pecado de) origen de la Constitución de 1980 no sea decisivo pero sí que indique que "el problema constitucional está efectivamente en el origen". ${ }^{6} \mathrm{El}$ origen dictatorial de la Constitución de 1980 es lo que indica que sus regulaciones hayan sido diseñadas para hacer imposible la agencia política del pueblo y que, por lo tanto, el pueblo no pueda apropiarse, porque su agencia está maniatada, de las regulaciones constitucionales ilegítimas en su origen.?

\footnotetext{
${ }^{5}$ Atria (2013), p. 63.

${ }^{6}$ ATRIA (2013), p. 64.

${ }^{7}$ ATRIA (2013), p. 64-5
} 
Pero que forma sea fondo significa algo más. Significa, en lo que acá nos interesa destacar, que es solo recurriendo a un procedimiento (como la asamblea constituyente) es posible dotarnos de una Nueva Constitución. Esto es, una nueva decisión sobre la forma y existencia de nuestra comunidad política cuya validez depende de la decisión constituyente y no del hecho que esa decisión depende, en su validez, "en algo anterior a la constitución". 8 No en vano en la teoría constitucional contemporánea, el poder constituyente significa exactamente eso, que "el pueblo, ejerciendo su soberanía (popular), puede adoptar la constitución que desee". Como afirma Kalyvas, las reglas, normas e instituciones fundamentales presentan la paradoja de ser producto de la voluntad no regulada, normada ni institucionalizada del poder constituyente, el que es, además, su origen. ${ }^{10}$ Esto es lo que quiere sugerir la idea de 'hoja en blanco' o 'partir de cero' que se ha utilizado para describir un (genuino) proceso constituyente: se parte de cero no cuando se niega la historia, el pasado, la evolución-no obstante interrumpida por el terror-del constitucionalismo, sino cuando una nueva decisión constitucional "no está atada a decisiones anteriores". ${ }^{11}$

¿Es el proyecto de itinerario fiel a esta forma de concebir el poder constituyente $?^{12}$ La respuesta es negativa. No es fiel por cuanto el itinerario (i) pretende sujetar el proceso constituyente a reglas y procedimientos anclados en la Constitución vigente, de modo tal que hace improbable la apropiación del pueblo de ese proceso y que se trate de un genuino ejercicio de poder constituyente (que no está atado a decisiones anteriores). ${ }^{13}$ Pero, especialmente, no lo es porque (ii)

\footnotetext{
${ }^{8}$ ATRIA (2013), p. 69.

${ }^{9}$ COLÓN-Ríos (2012), p. 88.

${ }^{10}$ Kalyvas (2005), p. 228. Véase, también, LOUGHLin (2010), p. 225.

11 ATRia (2013), p. 72.

12 En sentido similar, ATRIA (2015), pp. 46-52 se refiere a la idoneidad del proceso, donde la idoneidad identifica la capacidad del proceso para solucionar el problema que se identifica. Si el problema que se identifica es la necesidad de cambiar la Constitución, y no solo reformarla, un mecanismo que descanse en las reglas constitucionalmente vigentes para su reforma, carece, precisamente, de esa capacidad.

${ }^{13}$ Las secciones siguientes abordan esta objeción proponiendo alguna forma de articulación democrática de lo que, no otra cosa, que un itinerario que se sujeta a reglas vigentes por cuestiones de evaluación política. La propuesta, no sobra señalarlo, se realiza desde la teoría constitucional y no juzga sobre la (existencia o no, corrección en la apreciación o no, etc. de la) evaluación política. Al respecto, el mismo ATRIA (2015), pp. 60-2 ha señalado que lo que es idóneo (en el sentido de hacer posible hablar de una Nueva Constitución) no parece ser viable políticamente. Esto mismo, sin embargo, es relevante para advertir que el itinerario presentado sobre la base del respeto al derecho vigente y los cauces institucionales no es, en verdad, eso, sino una cuestión de ethos político, de forma de hacer política y que alcanza al proceso constituyente. Una forma de hacer política, para decirlo de otro modo, que descansa en la convicción, autoimpuesta o no, de que cualquier cambio requiere del concurso de las $2 / 3$ partes de los miembros en ejercicio, aunque ello no sea así requerido por las regulaciones constitucionales ATRIA (2015), p. 45 n.5.
} 
subvierte la idea de poder constituyente confiriendo primacía a la forma sobre el fondo o, como diremos, transformado, por vía de esa preferencia sobre el fondo, a la forma en irrelevante.

De conformidad al itinerario, las etapas de educación cívica y cabildos ciudadanos van a producir, previa mediación de alguien que se encargará de su redacción, las 'Bases Ciudadanas para la Nueva Constitución'. Es decir, la participación es mediatizada una vez que es procesada en un documento que les da sentido. No es claro quién o qué metodología se utilizará para ello.

Además, esas 'Bases' no se traducirán, inmediatamente, en una nueva Constitución, sino que serán sometidas a una segunda mediación: serán leídas a la luz de "lo mejor de la tradición constitucional chilena y que esté acorde con las obligaciones jurídicas que Chile ha contraído con el mundo". ${ }^{14}$ Es decir, el procesamiento de la actividad producida en las dos primeras etapas tendrá un rasero de contenido que modulará el resultado que se conocerá como 'Bases'. Esa modulación se produce a través de la reconstrucción de la "mejor tradición constitucional chilena" y de "las obligaciones jurídicas que Chile ha contraído con el mundo" (que, cuando se habla de "mundo", debiese asumirse que se refiere a obligaciones internacionales).

El resultado de esa lectura será un proyecto de Nueva Constitución que la Presidenta someterá a conocimiento del actual Congreso. ¿Para qué? ¿Para que lo discuta y, de estimarlo procedente, lo apruebe? Esto no es claro, pero se puede suponer, en términos estratégicos, que el Congreso lo tendrá a la vista antes de proceder a habilitar (por $2 / 3$ de sus miembros en ejercicio, según el itinerario) al próximo Congreso Nacional electo en 2017.

Que esto supone la sujeción de las formas al fondo, al punto de hacer irrelevante las formas, lo evidencia la aspiración declarada del itinerario de que sea la instancia habilitada por el próximo Congreso, cualquier que se elija, la que se encarge de discutir el proyecto de Nueva Constitución elaborado por el Gobierno. Esto es, busca asegurarse que la discusión 'no parta de cero' o de 'una hoja en blanco', si no que, para seguir con la idea, que parta de 95 o 100 o de una hoja que lleva algo más que un simple bosquejo. ${ }^{15}$ Citamos a la Presidenta:

\footnotetext{
${ }^{14}$ Para decirlo de otro modo, las intervenciones ciudadanas no solo van a ser filtradas por quienes, y de conformidad a la metodología que estimen necesaria, se encargará de inducir bases constitucionales a partir de las preocupaciones generales que se manifestarán en los cabildos. Serán filtradas, además, cuando se reclame una expertise constitucional para desechar aquello que no sea posible encuadrar dentro de "lo mejor de la tradición constitucional chilena".

15 Se puede inferir que este proyecto busca dar "viabilidad política" a la opción por un mecanismo determinado. Es decir, para que los actuales o futuros parlamentarios voten a favor de un mecanismo de reemplazo de la Constitución de 1980 requieren, antes, una "idea" de los contenidos que se buscarían impulsar en cualquiera sea el mecanismo que se adopte. Ello daría "garantías políticas" a los distintos partidos con representación parlamentaria.
} 
"La instancia constituyente que el próximo Congreso elija, deberá discutir el proyecto enviado por el Gobierno, fundado en las Bases Ciudadanas para una Nueva Constitución.

Finalmente, este proyecto, una vez sancionado por dicha instancia, deberá ser sometido a un plebiscito vinculante, para su ratificación por parte de los ciudadanos."

Como se indicó al comienzo de este trabajo, esta fórmula de amarre ha sido advertida por parte de los parlamentarios del actual Congreso que debe concurrir con su voto a formar los $2 / 3$ que harían posible la habilitación al próximo Congreso. Así, el senador Hernán Larraín (UDI), afirmó que "se nos ha dado garantías de que antes de cambiar el capítulo de la reforma se va a conocer el contenido". " En los mismos términos, y advirtiendo el sentido preciso del itinerario, afirmó que esto significa que no van a "darle un cheque en blanco" al Gobierno para que termine imponiendo "una Constitución que, a lo mejor, no es lo que los chilenos quieren". ${ }^{17}$

Ahora estamos en condiciones de apreciar mejor los límites del itinerario propuesto. Cualquiera que sea el mecanismo que el próximo Congreso elija, su función se va a limitar sustantivamente a discutir el contenido (el fondo) del proyecto de Nueva Constitución elaborado por el Gobierno. Es decir, sea que se opte por el Congreso, por una comisión mixta o por una asamblea constituyente, en todos los casos el mecanismo (la forma) se transforma en irrelevante a la luz del mandato que le será impuesto: discutir el proyecto de Nueva Constitución que elabora el Gobierno y que servirá, primero, para hacer posible (políticamente) la habilitación del actual Congreso y, segundo, para sujetar sustantivamente el trabajo de las instancia que elija el próximo Congreso.

\section{El cauce institucional}

De todo lo dicho hasta acá no debe concluirse la irrelevancia de las instituciones. Del hecho que el ejercicio del poder constituyente no dependa de la sujeción a regulaciones previas que, tanto desde el punto de vista de la forma como en el fondo, definen los márgenes dentro de los que pueda moverse la decisión sobre una nueva Constitución, no se sigue, que no pueda ser posible un diálogo entre las instituciones constitucionales que desean ser superadas y el proceso (adecuado,

16 “DC y RN reviven diálogos políticos y agendan primera cita por nueva Constitución”, La Tercera, 17 de octubre 2015, p. 12.

${ }^{17} \mathrm{Id}$. 
como hemos dicho) para hacer posible esa superación por medio de una nueva Constitución.

Es posible, así, afirmar que la institucionalidad es irrelevante y relevante para el proceso constituyente. Es irrelevante por las razones antes dadas: solo hay ejercicio legítimo de poder constituyente allí donde la decisión constitucional se toma sin que "algo anterior a la constitución" 18 determine las condiciones de validez de esa decisión. La institucionalidad, al mismo tiempo, es relevante, aunque lo es en un sentido diverso y que ahora exponemos.

En rigor, la relación entre institucionalidad y no institucionalidad se verifica ya en el acto fundacional mismo al establecerse un sistema entre ambos momentos y se proyecta durante el funcionamiento regular del orden institucional. ${ }^{19}$ En palabras de Loughlin, es la práctica social del ejercicio del poder del Estado el que nos permite superar la división estricta entre el lado sociológico del poder, de una parte, y su lado legal, de otra. ${ }^{20}$

El estado de excepción, el verdadero momento en que la fuerza del soberano se manifiesta, necesita a la institucionalidad (y a las reglas legales) para su propia validez. El derecho y las instituciones, por su parte, son el producto de la reafirmación de la decisión adoptada en el momento excepcional. ${ }^{21}$ Así como la Constitución, y el orden legal que a su amparo se configura, se evidencia como "la verdad íntima de la revolución [...] la excepción revolucionaria es la verdad íntima de la constitución," como observara Kahn. ${ }^{22}$ Un innegable indicador de que "la decisión constitucional no se refiere exclusivamente a una quaestio iuris ni a una quaestio facti, sino que a la relación misma entre derecho y facticidad", en palabras de Agamben. ${ }^{23}$ La relación, así, entre poder constituyente y poder constituido, es-como la del esclavo y el amo, en Hegel-una de paradójica mutua necesidad. ${ }^{24}$

Esta es la paradoja de la soberanía; el hecho de que el poder constituyente se encuentre, a un tiempo, "dentro y fuera del orden jurídico". ${ }^{25}$ Como lo indica Loughlin, el Estado y sus instituciones, junto a su orden constitucional, solo pueden comprenderse en la medida que seamos capaces de anotar ambas caras de

\footnotetext{
${ }^{18}$ ATRIa (2013), p. 69.

19 De hecho, siguiendo a Nadia Urbinati, esta es, propiamente, la misma forma que adopta la democracia representativa: "en la democracia representativa, el soberano no se identifica por la sola referencia a las instancias formales de formación de voluntad, sino que en la relación dual en que esas instancias formales son un elemento relevante y que se suman a la opinión pública por medio de la que los gobernados participan indirectamente en el gobierno". URBINATI (2014), p. 135.

${ }^{20}$ Loughlin (2010), p. 221.

${ }^{21}$ Agamben (1998), pp. 15-25.

${ }^{22}$ KAHN (2011), p. 47.

${ }^{23}$ AgAmben (1998), p. 26.

${ }^{24}$ LOUGHLIN (2010), p. 227.

25 AgAmben (1998), p. 15.
} 
su conformación: su cara sociológica y su cara jurídica. ${ }^{26}$ Favorecer solo una de esas caras, o presentarla como todo y lo único que importa, prescinde del equilibrio reflexivo en que facticidad y validez se expresan $y$, de este modo, afecta la legitimidad (tanto constituyente como de política ordinaria) que de ella emana. ${ }^{27}$ De allí que el itinerario que acá repasamos, no obstante pretende que el proceso constituyente arranque desde (y no de) las regulaciones vigente, no es idóneo en tanto momento constituyente. Porque al sujetar el proceso constituyente a las reglas vigentes - bajo la excusa de conferir cauce legal al itinerario-hace imposible su superación. Para que la relación relevante/irrelevante de la institucionalidad pueda verificarse en un proceso constituyente, como hemos dicho, se necesita hacer posible, no obstante una relación, una inevitable ruptura con las regulaciones vigentes. El itinerario, tal como se advierte, en cambio, subsume el proceso en la regulación vigente y la transforma en resultado de sus instancias constituidas.

¿Es posible salvar el itinerario, al menos en el sentido que acá se indica? ${ }^{28}$ Creemos que sí, y por ello avanzamos en la relectura democrática del mismo. Una lectura, como se ha dicho más arriba, que haga idóneo el itinerario y que, de paso, lea adecuadamente las mismas reglas que se citan en su apoyo.

\section{El derecho vigente}

De acuerdo a lo sostenido en la primera parte de este artículo, la solución constituyente no puede quedar sometida a las reglas preconcebidas del entramado constitucional vigente. $Y$ no puede serlo no solo porque traiciona la idea misma de proceso constituyente, sino también porque la Constitución actual no establece un procedimiento de sustitución de la Constitución. De esta forma, la necesidad de que, para que dé como resultado una nueva Constitución, el proceso constituyente que no quede sometido a las reglas vigentes no es una rechazo de la exigencia de que sea "institucional" sino, por el contrario, una constatación de que precisamente para que sea institucional el derecho vigente es insuficiente.

\footnotetext{
${ }^{26}$ LOUGHLin (2010), p. 221.

27 Esto amerita una breve aclaración. Que 'afecte' la legitimidad de las decisiones gubernativas quiere decir que estas decisiones siguen siendo jurídica y formalmente válidas. En cambio, que 'afecte' la decisión constituyente posee consecuencias, en línea con lo dicho antes, más intensas: hace imposible el ejercicio del poder constituyente que, en estos términos es inidóneo para producir el resultado que esperaba producir, a saber, una Nueva Constitución. ¿Que de todas formas producirá efectos jurídico formales? Por supuesto, pero solo en tanto reforma a la Constitución.

28 Algunos de nosotros habíamos avanzado ya la posibilidad de establecer este vínculo por medio de un plebiscito de apertura del proceso constituyente. Ello no lo abordamos acá. Véase CONTRERAS y LOVERA (2015). Para una propuesta distinta, que incluye plebiscito vinculante para elegir el mecanismo de reemplazo, véase Riffo Elgueta (2016).
} 
El itinerario constituyente anunciado propone, en efecto, la incorporación de nuevas reglas en la Constitución de 1980 para llevar adelante el proceso constituyente y habilitar la redacción de una nueva Constitución. El anuncio presidencial no es explícito respecto de si esas nuevas reglas se incorporarían por medio de la creación de un nuevo capítulo de la Constitución (un capítulo XVI, por ejemplo), o si por medio de la mera modificación de los preceptos contenidos en el capítulo XV que establece las normas sobre reforma de la Constitución.

Sin embargo, la ausencia de un mecanismo para reemplazar la Constitución vigente es negada por buena parte de la élite política, así como de la academia. Por el contrario, se afirma que las reglas del capítulo XV de la Constitución, que trata sobre "Reforma de la Constitución", permitirían reemplazar completamente el texto constitucional. En la academia, por ejemplo, Francisco Zúñiga ha afirmado que "[1]a reforma total (poder constituyente derivado) es un camino posible [para generar una nueva Constitución] dado que el Capítulo XV de la Constitución no impone límites materiales (explícitos o implícitos y temporales". ${ }^{29}$

En la élite política, por su parte, distintos legisladores comparten esa tesis. Así, por ejemplo, los senadores Osvaldo Andrade, Marcelo Schilling, y Guillermo Ceroni presentaron un proyecto de ley titulado "Reforma constitucional que sustituye cada uno de los Capítulos de la Carta Fundamental", el que afirma entre sus ideas matrices tener "por finalidad sustituir de manera íntegra los quince capítulos vigentes de la Constitución Política de 1980". 30

Más aun, durante la tramitación del proyecto que terminaría siendo la Ley 20.050 (la reforma constitucional de 2005), algunos senadores fueron de la opinión que como el procedimiento del capítulo XV de la Constitución permite reformar cualquier parte de ella, en el sentido de que -a diferencia de constituciones como la francesa o la alemana- no hay en la Constitución vigente disposiciones inmodificables, y en tanto que, además, no se señala un límite en cuanto a la cantidad de artículos que pueden modificarse en una sola reforma, en efecto el legislador puede llevar a cabo una "reforma" total.

La tesis fue defendida por los senadores Andrés Chadwick, Sergio Fernández, y Andrés Zaldívar. Durante la tramitación de la reforma, en la sesión en sala del 29 de abril de 2003, el designado Jorge Martínez Busch sostuvo que el proyecto de reforma modificaba totalmente el espíritu de la Constitución, y que faltaba en el proceso, por tanto, "una instancia fundamental", a saber, escuchar "a quienes en definitiva constituyen el Poder soberano". Sin que nadie se pronunciara sobre quiénes constituyen ese poder, el senador Chadwick se apresuró a dejar en claro que no había irregularidad alguna, pues el procedimiento de reforma del capítulo XV no contempla ningún procedimiento especial -como escuchar al

29 ZÚÑIGA (2015), p. 200.

30 Boletín 10193-07. 
soberano-, cualquiera fuera la magnitud de la reforma constitucional, "sea que se modifique un inciso de un artículo", dijo, "o diez, veinte, treinta, cuarenta o cincuenta preceptos de la Carta". El senador Fernández gritó entonces " $\mathrm{O}$ todos!", y Chadwick concurrió: "O todos los artículos". Finalmente Zaldívar, Presidente del Senado en ese momento, sostuvo: "La Mesa coincide con Su Señoría. El Parlamento mantiene su poder constituyente y nadie hasta este momento se lo ha limitado ni quitado. Además, cumpliéndose los requisitos, podemos reformar la Constitución Política en todos y en cada uno de sus contenidos". ${ }^{31}$

Más recientemente, el senador Andrés Allamand ha afirmado que la tesis según la cual "la Constitución actual no establece un mecanismo para ser reemplazada" es "equivocada", y que bajo las reglas vigentes "promoviendo un proyecto de reforma constitucional, si existen las mayorías, la Constitución se puede reemplazar del primero al último artículo". ${ }^{32}$

La tesis de los senadores citados es errónea. Bajo las normas del texto constitucional vigente no es lícito que por medio del procedimiento del capítulo $\mathrm{XV}$ se reemplace la Constitución, pues se trata de un procedimiento cuyo propósito es, precisamente, reformar la Constitución, no reemplazarla. En otras palabras, la Constitución vigente no regula la facultad de reemplazo, sino solo de reforma. ${ }^{33}$ Por tanto, ningún órgano puede, sin contravenir el artículo $7^{\circ}$ de la Constitución, ejercer la facultad de reemplazo. Al hacerlo estaría actuando fuera de su competencia, pues es patente que las expresiones "reforma" y "reemplazo" expresan significados distintos, de manera que la primera implica la modificación de algo conservando su identidad, mientras que la segunda implica una sustitución, poner algo nuevo en lugar del objeto original. Reemplazar la Constitución por medio del procedimiento del capítulo XV sería excesivo.

La Corte Constitucional colombiana resume los argumentos precedentes de la siguiente forma, plenamente aplicables en nuestro caso:

Una cosa es que cualquier artículo de la Constitución puede ser reformado -lo cual está autorizado puesto que en eso consiste el poder de reforma cuando la Constitución no incluyó cláusulas pétreas ni principios intangibles de manera expresa, como es el caso de la colombiana-y otra cosa es que so pretexto de reformar la Constitución en efecto esta sea

\footnotetext{
${ }^{31}$ Biblioteca del Congreso Nacional (2005), Historia de la Ley N²0.050, pp 1442-1443.

32 "No creo que debamos participar de este aparataje que se está montando", La Tercera,1 de noviembre 2015, p. R12.

33 Véase Riffo Elgueta (2016) para más argumentos (semánticos, jurídicos, y políticos) sobre la distinción.
} 
sustituida por otra Constitución totalmente diferente, lo cual desnaturaliza el poder de reformar una Constitución y excedería la competencia del titular de ese poder. ${ }^{34}$

Ahora, que la distinción conceptual sea en abstracto clara no conlleva que la determinación en concreto de cuándo nos encontramos frente a un caso de reemplazo o de sustitución sea sencilla o pacífica. La dificultad para determinar en concreto el límite entre reforma y reemplazo se explica por el hecho de que supone un juicio acerca de qué constituye la identidad -la "esencia", si se quieredel objeto en cuestión. En el caso de la Constitución, será desde luego una cuestión polémica, pero debe notarse que la existencia de la distinción no permite por sí misma que esa determinación deba correspondería a un sujeto u órgano específico (al Tribunal Constitucional, por ejemplo), aunque la tesis de la soberanía popular exige que tal juicio corresponda al pueblo. ${ }^{35}$

Sin embargo, al menos lo siguiente debería ser pacífico: es incorrecto asumir que lo que distingue a una Constitución de su sucesora es simplemente un criterio cuantitativo, de manera que si se modifican todos los artículos el resultado será necesariamente una nueva constitución. Lo que importa para propósitos de establecer la identidad de una constitución no está en una o más de sus normas, sino en un elemento sustantivo que podríamos llamar de diversas formas: el espíritu de la Constitución, sus principios esenciales o supremos, su instituciones fundamentales, etcétera. ${ }^{36}$ Ahora, ¿cuáles son esos elementos sustantivos que determinan la identidad de la constitución? esta es una cuestión política -en efecto, soberana- y, por tanto, profundamente polémica. Habrá quienes afirmen que se trata de cierta filosofía política, o económica, o de un diseño institucional 'tramposo'; habrá quienes afirmen que esa esencia es valiosa, o que es nefasta. Por cierto, también puede tratarse de su origen, y lo que ello implica para su legitimidad. Puede, por último, tratarse una compleja combinación de estos elementos.

Ahora, más allá de cuáles sean los criterios de identidad de la Constitución vigente (sobre lo que no nos pronunciaremos), ella no otorga a ningún órgano la facultad de poner en su lugar una nueva. A fortiori, puede afirmarse que no considera tampoco un mecanismo para ejercer esa facultad. Sin embargo, sí contempla un procedimiento (el del capítulo XV) que podría utilizarse para lograr el efecto de reemplazar el texto completo de la Constitución, dando lugar a la imposición de una nueva. Sin embargo, la posibilidad de utilizar un mecanismo

\footnotetext{
${ }^{34}$ Corte Constitucional de Colombia (2003): 9 de julio de 203, sentencia C-551/2003, considerando 33.

35 Véase la sección 4, infra, para el análisis de la situación del Tribunal Constitucional chileno frente a un proceso consituyente.

${ }^{36}$ Véase BERNAL (2013) para una evaluación crítica de los criterios de identidad propuestos por la Corte Constitucional colombiana, junto con una propuesta al respecto para el contexto de democracias hiperpresidenciales como la colombiana (o, por cierto, la nuestra).
} 
jurídico para lograr un efecto es algo distinto de la atribución de la facultad para realizar ese efecto, y ninguna implica la existencia de la otra. Así, es posible la atribución a un órgano de una facultad sin que exista el mecanismo para ejercerla (porque, por ejemplo, no se ha dictado su ley orgánica), tanto como es posible que exista un procedimento que permita lograr un efecto para el cual no se ha reconocido la facultad (por ejemplo, si se crea una norma inconstitucional sujeta a control de constitucionalidad eventual, pero este nunca se realiza). Dadas las consideraciones anteriores, si bien el artículo 127 permite lograr un resultado similar al que el ejercicio de la facultad de reemplazo permitiría, la Constitución no contempla esa facultad, de manera que utilizarlo, como proponen los senadores, para ese efecto sería una actuación que excedería las competencias que se le reconoce al legislador. Sería, en efecto, un "atajo".

La conclusión forzosa de los razonamientos previos es que la facultad de reemplazo debe ser incorporada a la Constitución. Lo natural sería que se incorporara en un nuevo capítulo que trate, precisamente, sobre la "Reemplazo de la Constitución", utilizando (correctamente) el procedimiento del capítulo XV, y cumpliendo con el quórum de 3/5 exigidos por esas normas para toda reforma que no recaiga sobre los capítulos taxativamente listados en el artículo 127. Sin embargo, parece darse por sentado que las modificaciones normativas para hacer posible el reemplazo de la Constitución vigente requerirían satisfacer el quórum de $2 / 3$ de los senadores y diputados en ejercicio. Es más, suelen denunciarse como "atajos" aquellas tesis que sostienen la suficiencia de un quórum de 3/5 para lograr los mismos fines.

Sin embargo, la idea de que el quórum aplicable sería el de $2 / 3$ es injustificada en un doble sentido. En primer lugar, porque no se han ofrecido argumentos a favor de ella. En segundo lugar, es injustificada en el sentido de que es errónea, específicamente, en términos conceptuales.

Respecto de lo primero, pareciera que por razones políticas se pretende imponer como si se tratase de un hecho indiscutible, cuando es, en realidad, una posición jurídicamente polémica. Esta sola omisión es inexcusable desde el punto de vista de la deliberación democrática que exige un proceso como este.

Un ejemplo de lo anterior es la opinión de Patricio Zapata quien afirma que "para efectos de los cambios constitucionales más importantes" debe cumplirse el quórum de 2/3. Aunque anuncia que haría "razones de doctrina" para sostener lo anterior, ellas no se ofrecen. Desde luego, simplemente invocar la "importancia", sin siquiera ofrecer criterios para determinarla, ni hacer referencia al texto constitucional para justificar la tesis es argumento suficiente.

${ }^{37}$ ZAPATA (2015), p. 179. 
Para poder enmarcar un debate por medio de razones debe, primero, fijarse lo que es no es polémico en esta discusión, a saber, que el artículo 127 de la Constitución dispone para la aprobación de reforma a su texto obtener en "cada Cámara el voto conforme de las tres quintas partes" de los diputados y senadores en ejercicio, y que si "la reforma recayere sobre los capítulos I, III, VIII, XI, XII o XV, necesitará, en cada Cámara, la aprobación de las dos terceras partes" de los mismos.

La interpretación natural de la disposición citada es que la regla general para reformar la Constitución es la de los 3/5. La regla de quórum de $2 / 3$ rige -siguiendo el método de interpretación estricta propio del derecho público- para los casos excepcionales expresamente mencionados. En otros términos, la excepción de $2 / 3$ solo se aplica para los capítulos taxativamente enumerados en el artículo 127 . Se sigue de esto que para la incorporación de un nuevo capítulo rige el quórum general de modificación de la Constitución: $3 / 5$ de los diputados y senadores en ejercicio. Al respecto ya existe precedente bajo la vigencia de la Constitución de 1980. En efecto, la incorporación del nuevo capítulo sobre el Ministerio Público se hizo satisfaciendo la regla general del quórum de $3 / 5{ }^{38}$ Dado lo anterior, la afirmación de que sería necesario satisfacer el quórum de $2 / 3$ para incorporar un capítulo XVI que regule el reemplazo de la Constitución es injustificada.

El argumento más previsible que pudiera esgrimirse a continuación en contra del argumento anterior sostiene que la regulación de un mecanismo de reemplazo constitucional es una materia propia del capítulo XV, de manera que las reglas sobre el reemplazo de la constitución deberían ser reguladas en el capítulo XV, $\mathrm{o}$, al menos, satisfacer el quórum de este último. En este sentido se ha escrito que:

Una regla de elemental lógica lleva a concluir que cualquier regla que tenga por objetivo innovar sobre cómo se modifica el texto de la Constitución, total o parcialmente, debe incluirse en el capítulo de Reforma Constitucional y aprobarse por el quórum de $2 / 3 .^{39}$

Tal argumento extensivo, sin embargo, es incorrecto por las razones ya dadas. En resumen: La Constitución vigente solo regula su reforma, y no regula, en cambio, su reemplazo. Al confundir reforma y reemplazo, este argumento es una manera engañosa de eludir la regla general de los $3 / 5 .^{40}$

Pudiera, en este punto, objetarse la distinción afirmando que la facultad de reformar la Constitución contiene a la de reemplazarla. Se trata de una variación del argumento a fortiori, como lo ha sostenido Hernán Corral. El autor afirma que:

\footnotetext{
38 Véase Biblioteca del Congreso Nacional (1997), Historia de la Ley $N^{\circ} 19.519$, pp. 15 y 85. Concordante, en este sentido, Barrientos (2015).

39 “Quórum para una Nueva Constitución”, El Mercurio, 19 de octubre 2015, p. A3.

40 En efecto, la idea de reforma o modificación "total" son formas engañosas de referirse al reemplazo constitucional.
} 
La interpretación que cabe hacer, por tanto, debe ser guiada por el argumento lógico-jurídico llamado 'a fortior' (con mayor razón), en una de sus dos versiones: a minore ad maius, y que popularmente se explica con la fórmula de 'quien no puede lo menos no puede lo más'. Aplicando el argumento a [este] caso, se verifica que si no se puede hacer una reforma de la Constitución por tres quintos (lo menos), con mucha mayor razón no puede decidirse por ese quórum reducido un procedimiento para su íntegro reemplazo (lo más). ${ }^{41}$

Pero tal argumento es erróneo por varias razones. En primer lugar, interpreta una facultad (la de reformar) como si se tratase de una probibición. Esto es incorrecto pues la facultad otorgada está delimitada por el ámbito de competencia respectivo (un límite interno), y no por prohibiciones que limiten (desde fuera, por así decirlo) una facultad en principio ilimitada. El razonamiento 'quien no puede lo menos no puede lo más' es válido cuando se trata de determinar la extensión de una prohibición que limita una libertad que existe con independencia de la atribución de una facultad. En otras palabras, el argumento puede ser válido en el contexto de la acción de privados (cuyo ámbito de actividad lícito es en principio ilimitada), pero no en el de órganos públicos respecto de los cuales toda posible actuación lícita es definida normativamente.

Pero además, el argumento de Corral asume que la distinción entre reforma y reemplazo es una cuestión de grados, lo que es erróneo. Tanto el sentido semántico como el sentido político de las ideas de reforma y reemplazo son cualitativamente distintos. De otra forma no se entendería la discusión pública del último par de años entre quienes abogan por el reemplazo de la Constitución y quienes se conforman con su reforma "parcial". Después de todo, la distinción entre reforma y reemplazo marca la diferencia entre el ejercicio limitado del poder estatal y aquel que solo es restringido por el arbitrio de quienes lo detentan. Esto último es, desde luego, inaceptable bajo un Estado de Derecho.

Pudiera, finalmente, insistirse en la existencia de alguna forma de inconsistencia entre la posibilidad incorporar un mecanismo de reemplazo en la Constitución por medio de un quórum inferior al necesario para reformar algunas de sus partes. Sin embargo, tal argumento descansa sobre una confusión, a saber, aquella entre el quórum necesario para la incorporación de un capitulo nuevo y el quórum para el ejercicio de la facultad de reemplazo que ese capitulo regularía. Es decir, son conceptualmente diferentes el quórum para crear un nuevo capítulo de la Constitución que el exigido para adoptar una decisión constituyente ejecutando

41 CORRAL (2015) https://corraltalciani.wordpress.com/2015/10/18/proceso-constituyente-yargumento-a-fortiori/ 
una potestad de sustitución del texto mismo de la Constitución. La preocupación de quienes exigen $2 / 3$ debiera estar en esto último.

Sin embargo, esta última preocupación se disuelve cuando el pueblo es convocado a ejercer la potestad constituyente de la cual es natural titular; la supuesta inconsistencia desaparece si el ejercicio de la facultad de reemplazo se reconoce al pueblo. Para entender por qué debe observarse que, bajo las reglas constitucionales actuales, la decisión mayoritaria en plebiscito tiene precedencia respecto de la decisión de las autoridades constituidas, incluso cuando si esta última se adopta por 2/3. En efecto, bajo las reglas vigentes, si existe desacuerdo respecto de una reforma constitucional entre el Congreso y el Ejecutivo, la Constitución prevé la posibilidad que el Presidente de la República someta la decisión a plebiscito. En tal caso, es el pueblo quien decide por mayoría, derrotando, en su caso, la decisión del Congreso adoptada por 2/3. En esa decisión plebiscitaria, desde luego, no se aplican supermayorías. Además, esta es la única solución consistente con el artículo $5^{\circ}$, el que reconoce primariamente el ejercicio de la soberanía al pueblo, y "también" a las autoridades constituidas. Es más, aquellos que afirman que el proceso constituyente debe terminar con un plebiscito ratificatorio ${ }^{42}$ asumen, implícitamente, la prioridad de la decisión popular mayoritaria sin sujeción a quórums especiales. Quizás sus intuiciones sean más democráticas que lo que el procedimiento propuesto pueda lograr.

\section{Vinculatoriedad del proyecto de nueva Constitución a una instancia constituyente y la posibilidad de control jurisdiccional}

Una de las cuestiones que no se resuelven del anuncio del itinerario constituyente es la vinculatoriedad u obligatoriedad que puede tener un proyecto de nueva Constitución elaborado por el Presidente de la República, sobre las 'Bases' definidas y con las mediaciones aquí explicitadas. En otros términos, cabe preguntarse si el proyecto sujeta al mecanismo. La pregunta, evidentemente, no es baladí: su respuesta determina genuinamente la posibilidad de un proceso constituyente en el que la forma determina el contenido.

La respuesta puede ser ilustrada a partir de las opciones de mecanismos para la adopción de una nueva Constitución. En general, se puede afirmar que el proyecto de nueva Constitución es obligatorio y vinculante para las instancias

42 Existen numerosos autores que suscriben la propuesta de plebiscito ratificatorio (con independencia del mecanismo procedimental escogido para una nueva Constitución). Véase, entre otros, Correa SutIL (2015), p. 125 (el plebiscito "puede ser necesario"); GARCía y VERdugo (2015), p. 142-3 (denotando la "importancia" del plebiscito ratificatorio porque "reflejaría el compromiso del pueblo con una nueva Constitución”); SZMULEWICZ (2015), p. 161 (plebiscito como una "condictio sine qua non" del proceso constituyente); Zapata (2015), p. 181; CONTRERAS y LOVERA (2015), p. 238 (destacando el plebiscito habilitante y ratificatorio); BASSA y SALGADO (2015), p. 265; GARRETÓN (2015), p. 314, y RifFO ELGUETA (2016). 
constituidas, como una comisión bicameral o el comité de expertos. Pero ello no es claro respecto de la Asamblea Constituyente. Aceptar que el proceso tiene el carácter de constituyente supone asumir que la instancia deliberativa que adopta el texto de la nueva Constitución es soberana. Si la Asamblea es depositaria de la soberanía en la que se ejerce la potestad constituyente, entonces no puede quedar sujeta al proyecto enviado por los poderes instituidos.

El problema se traslada hacia quién controla la obligatoriedad (o cuánto puede el Derecho someter un proceso como este). ¿Quién sería el contralor o el árbitro del proceso constituyente? Tal proceso, ¿puede ser sometido, por ejemplo, a una decisión jurisdiccional?

Nótese que esta pregunta se conecta con la revisión de la implementación procedimental del itinerario constituyente. De acuerdo a lo anunciado, la Presidenta de la República debería enviar un proyecto de reforma constitucional para incorporar cuatro posibles mecanismos que permitirían dictar una nueva Constitución y reemplazar la vigente. Hoy no existen reglas que permitan hacer esto. Como correctamente afirmó la Presidenta, "la actual Constitución no contempla mecanismos para elaborar una nueva Carta Fundamental". Frente a esto surge una serie de preguntas (a algunas de las cuales ya nos hemos referido): ¿debe hacerse una reforma al Capítulo XV de "Reforma a la Constitución" o corresponde incorporar un capítulo nuevo? ¿O bastaría, en cambio, con una disposición transitoria? ¿Cuál es el quórum que rige para esta modificación constitucional? Quizás, el resumen políticamente relevante de todas preguntas es uno solo: ¿Quién decide (o resuelve), en último término, todas estas preguntas? Como se observa, estas preguntas se relacionan con los marcos competenciales definidos en el itinerario constituyente.

Formulada así la interrogante, se devela la importancia de todo esto y se asoma el Tribunal Constitucional. ¿Puede este órgano -custodio de la Constitución vigente- ser el custodio del proceso constituyente? ¿Tiene jurídicamente la competencia para ello? Desde una lectura genuinamente democrática, la respuesta no admite doble lectura: no. El Tribunal Constitucional no puede ser el último contralor de la decisión soberana por excelencia, la decisión constituyente.

Para explicar esto, volvamos al caso. La Presidenta decide enviar un proyecto de reforma constitucional para habilitar el reemplazo de la Constitución vigente. El proyecto de reforma enviado crearía, supongamos, un nuevo Capítulo XVI. Las cámaras acuerdan que esta modificación debe votarse con el quórum de $3 / 5$ de los parlamentarios en ejercicio. Sin embargo, imaginemos, un grupo de ellos se opone. Son poco más de $1 / 3$ de diputados o senadores en ejercicio, que creen que no hay que cambiar la Constitución 1980 y que cualquier reforma de este estilo debería ser aprobada por $2 / 3$ (incluso más, bastaría con $1 / 4$ de cada 
Cámara para desafiar la decisión en el Tribunal Constitucional). El proyecto, no obstante, es aprobado por el quórum de 3/5. Desafiando la voluntad manifestada por el Congreso, los opositores acuden al Tribunal Constitucional para declarar la inconstitucionalidad del mecanismo de reemplazo. ¿Quién debe resolver una pregunta tan trascendental como esta?

El Tribunal Constitucional no tiene competencia en esta materia. Si bien hay discusión sobre la competencia del Tribunal para declarar la inconstitucionalidad de reformas constitucionales, no se ha discutido sus atribuciones en el evento de la sustitución de una Constitución. ${ }^{43}$ El artículo 93 n. ${ }^{\circ}$ 3 no faculta al Tribunal para resolver sobre el procedimiento adoptado para crear una nueva Constitución, muchos menos sobre su contenido. La pregunta planteada ante el Tribunal demuestra los límites de la jurisdicción. Los tribunales incluso aquellos con competencias constitucionales- no puede avocarse la decisión de este tipo. Tal autoarrogación de poder minaría las bases esenciales del Estado de Derecho.

El argumento no es más que una confirmación de algo que el mismo Tribunal Constitucional ha sostenido en su misma jurisprudencia. En el famoso y polémico caso, "Clodomiro Almeyda", el Tribunal declaró que no podía juzgar la legitimidad o ilegitimidad de la Constitución ya que, en sus propias palabras, "hacerlo importaría arrogarse una facultad que no se le ha conferido y lo que es más grave situarse por sobre el Poder Constituyente originario". "Y esto, a la vez, debe ser evidente para los demócratas. El poder constituyente recae en el pueblo, titular único de la soberanía. Un tribunal no puede arbitrar el reemplazo de una nueva Constitución porque, de lo contrario, se arrogaría extraordinariamente la potestad constituyente. En otras palabras, usurparía la soberanía.

A decir verdad, esta es una delgada línea por la que se mueven los tribunales o cortes encargadas de velar por el respeto a la Constitución. Frente a un proceso constituyente, como el acá descrito pretende serlo, ¿qué debe hacer un tribunal que, en tiempos normales, debería cuidar el respeto de las disposiciones constitucionales? Alguna corte de la región se han visto frente a casos similares y conviene mirar como ellas, tal como su par chilena, han sabido, adecuadamente, dar un paso al costado cuando la política constituyente está desarrollándose.

En 1990, la (entonces) Corte Suprema de Justicia de Colombia decidió sobre la convocatoria a una Asamblea Constituyente. ${ }^{45}$ Tal como parece ocurrir aquí, allí también se evidenció un tránsito por medio de canales institucionales

\footnotetext{
43 ZÚÑIGA (2006) y HENRíQUEZ (2011) interpretan de manera restringida las facultades de control del Tribunal Constitucional en el caso de reformas constitucionales, limitándolas a aspectos formales. NOGUEIRA (2006), en cambio, afirma que existen límites materiales al poder de reforma constitucional.

44 Tribunal Constitucional de Chile (1987): 21 de diciembre de 1987, Rol N 46, considerando 36.

${ }^{45}$ Corte Suprema de Justicia de Colombia (1990): 9 de octubre de 1990, Sentencia 138.
} 
vigentes y con el objeto de proceder al ejercicio del poder constituyente. La diferencia, claro está, es que la situación política de Colombia era de alta inestabilidad política. Prueba de ello lo constituye el hecho que, el acto que la Corte debía controlar, era un decreto que convocaba al pueblo de Colombia a elegir una Asamblea Constituyente y que había sido dictado por el Presidente de la República en virtud de facultades a las que tuvo recurso por encontrarse vigente una declaración de estado de sitio. ${ }^{46}$ Ahora bien, no obstante se trataba de facultades excepcionales, existía trás ellas un considerable apoyo político obtenido por medio del recurso a la denomina 'séptima papeleta, 47

En cualquier caso, la Corte afirmó su competencia para pronunciarse al respecto -no obstante el itinerario político-constituyente establecidoprecisamente por tratarse de un proceso que se iba construyendo por medio del ejercicio de atribuciones constituidas. ${ }^{48}$ Nada muy distinto, como venimos diciendo, de lo que podría ocurrir acá:

${ }^{46}$ El decreto 1926, dictado bajo el título de "Medidas tendientes a restablecer el orden público, consistentes en la convocatoria al pueblo para que elija una asamblea nacional que reforme la Constitución vigente", se estimó que era la única vía adecuada para superar el momento de tensión política que se vivía. De hecho, parte de las razones que el Presidente César Gaviria expuso para proceder de tal forma, era la certeza que, de tener éxito la convocatoria, algunos grupos guerrilleros depondrían las armas. COLÓN-Ríos (2012), p. 93.

${ }^{47} \mathrm{Al}$ respecto, consúltese TORRES (2007).

48 Previamente la Corte se había pronunciado afirmativamente frente al decreto 927, que fue el decreto que, en rigor, siguió a la presión política ejercida por medio del recurso a la denominada 'séptima papeleta'. Allí la Corte había ya aceptado la conexión entre fuerte perturbación del orden público y el recurso a la asamblea constituyente como medio para su superación. En Corte Suprema de Justicia de Colombia (1990): 24 de mayo de 1990, Sentencia 59, V.c, se lee:

El clamor popular para que ocurra el fortalecimiento institucional es un hecho público y notorio que en derecho no requiere prueba; en favor de él se han manifestado los partidos políticos, los medios de comunicación, los estamentos universitarios y el pueblo en general, a través de la denominada "séptima papeleta", en las elecciones del 11 de marzo de 1990.

Establecida como esta la veracidad de las premisas anteriores, resulta explicable la procedencia de la medida tomada en el decreto que se revisa, la cual para la Corporación está íntimamente ligada con las causas de la crisis y se dirige inequívocamente a conjurar sus efectos.

A la Corte no le corresponde calificar la conveniencia de la medida que se toma, ni predecir si con ella se va a superar la crisis o si por el contrario se convertirá en una nueva frustración, su tarea se circunscribe a la aplicación de la norma jurídica sin olvidar eso sí que: "las normas constituyen realidades sociales y humanas, productos históricos que se originan en una colectividad para la protección de ciertos fines, valores o intereses reales y concretos. No son entidades metafísicas o simples proposiciones formales; existen las normas para ser aplicadas y realizadas en una determinada sociedad, con resultados y consecuencias también de carácter perfectamente real" (omitimos la referencia). 
Si bien, en sentencia de mayo 24 del presente año [por medio de la sentencia 59] se afirmó que con la votación que pudiese producirse en favor de la convocatoria de una Asamblea Constitucional, se confería un mandato político, también es cierto que el mecanismo utilizado para permitir la manifestación popular que convoque la Asamblea, es un decreto de Estado de Sitio, cuyo control le corresponde a la Corte según las normas citadas.

¿Qué decidió la Corte? ¿Cómo leyó la relación entre presión política por el cambio constituyente, de una parte, y el recurso a instrumentos normativos constituidos, por medio de los que se pretendía dar cauce institucional a dicho reclamo, de otra? En favor de la potestad constituyente del pueblo. ${ }^{49}$ Para decidir de este modo, la Corte echó mano a la idea de lo que denominó el 'Constituyente Primario':

Como la nación colombiana es el constituyente primario, puede en cualquier tiempo darse una constitución distinta a la vigente hasta entonces sin sujetarse a los requisitos que esta consagraba. ${ }^{50}$

Esta afirmación de la Corte está lejos de ser trivial. En efecto, como bien lo anota Joel Colón-Ríos, junto con validar la constitucionalidad del decreto ella procedió a declarar la inconstitucionalidad de las cláusulas del decreto que pretendían limitar el ejercicio de las facultades constituyente de la asamblea. ${ }^{51}$

\section{A modo de conclusión}

El itinerario constituyente propuesto por la Presidenta de la República abre el espacio para deliberar seriamente sobre la forma de generación de una nueva Constitución y los contenidos que esta debe adoptar. Sin embargo, las ambigüedades presentes tienen la potencialidad de neutralizar una participación democrática efectiva si no son recomprendidas al margen de las trampas constitucionales vigentes.

En este trabajo se alerta sobre el excesivo énfasis que el itinerario confiere a las formas constitucionales vigentes, mismas que, dada su contribución a la neutralización de la política, motivan su superación. Bajo la fórmula de un proceso que respete un cauce institucional -enfatizando, por ejemplo, el eventual carácter controlador que el proyecto de nueva Constitución podría cumplir- se corre el riesgo de terminar diluyendo la forma adecuada para que sea viable una Nueva

49 Véase CAjAs (2008), pp. 90-93.

${ }^{50}$ Corte Suprema de Justicia de Colombia (1990): 9 de octubre de 1990, Sentencia 138, V.5.

${ }^{51}$ COLÓN-Ríos (2012), p. 93. En palabras de la Corte:

Siendo la nación el constituyente primario y teniendo ella un carácter soberano, del cual emanan los demás poderes, no puede tener otros límites que los que él mismo se imponga, ni los poderes constituidos pueden revisar sus actos (V.6). 
Constitución en el fondo que la hace, justamente, improbable. Y esto no solo porque las condiciones donde ese fondo se definiría (expresadas en términos vagos aún en el itinerario) llaman a la cautela. Sino que, en especial, como se ha dicho a lo largo de este trabajo, porque el ejercicio de la potestad constituyente puede solo estar alojada en su verdadero depositario, el pueblo.

Que el pueblo sea el depositario del poder constituyente indica que solo aquellas formas no neutralizadas son las que hagan posible su agencia política y permitirán adoptar una Nueva Constitución. Pero, además, nos lleva a advertir algo que la preferencia del fondo por sobre la forma esconde. $\mathrm{Y}$ es que las autoridades constituidas no están habilitadas para reformar todo lo que quieran de la Constitución pues esa es, otra vez, una facultad reservada para el pueblo.

Nuestras dudas en torno al itinerario, que hemos tratado de exponer acá en su mejor luz, apuntan, precisamente, a llamar la atención sobre condiciones de materialización del proceso constituyente. Estas condiciones bien pueden terminar siendo, no otra cosa más que, como en 2005, cambios constitucionales. Pero en caso alguno verdadera emanación del corazón de la sociedad; porque esos textos constitucionales, así generados, "suele dictarlas una parcialidad dominante o engendrarlas en la soledad del gabinete un hombre que ni aun representa un partido". 52

\footnotetext{
${ }^{52}$ BELLO (1848), p. 35.
} 
Contreras, Lovera, Riffo - Proceso (¿)Constituyente(?)

\section{BIBLIOGRAFÍA}

* Agamben, Giorgio (1998): Homo Sacer: Sovereign Power and Bare Life. (Traducc. Daniel Heller-Roazen, Stanford University Press, Stanford).

* Atria, Fernando (2013): La Constitución tramposa. LOM Ediciones, Santiago.

(2015): "Sobre el problema constitucional y el mecanismo idóneo y pertinente", en Claudio Fuentes y Alfredo Joignant (eds.), La Solución Constitucional. Plebiscitos, asambleas, congresos, sorteos y mecanismos hibridos. Catalonia, Santiago, pp. 41-70.

* Bassa, Jaime y SAlgado, Constanza (2015): "Bases Constitucionales del Proceso Constituyente II: Principios y Mecanismos para una Asamblea Constituyente", en Fuentes, Claudio y Joignant, Alfredo (eds.), La Solución Constitucional. Plebiscitos, Asambleas, Congresos, Sorteos y Mecanismos Híbridos (Santiago, Catalonia).

* Bello, Andrés (1848): "Constituciones", en Agustín Squella, Andrés Bello: Escritos jurídicos, politicos y universitarios (Santiago, Lexis Nexis 2005), pp. 35-42.

* Bernal, Carlos (2013): "Unconstitutional constitutional amendments in the case study of Colombia: An analysis of the justification and meaning of the constitutional replacement doctrine", en International Journal of Constitutional Law, N 11(2), pp. 339-357.

* Biblioteca del Congreso Nacional (1997): "Historia de la Ley No. 19.519 Crea el Ministerio Público", disponible [en línea]: http://www.leychile.cl/Navegar/scripts/obtienearchivo?id=recursoslegales/10221.3/600 /1/HL19519.pdf (última visita efectuada 23.11.2015)

* Cajas, Mario (2008): El Control Judicial a la Reforma Constitucional: Colombia, 1910-2007 (Santiago de Cali, Universidad Icesi).

* Contreras, Pablo y Lovera, Domingo (2015): "Bases constitucionales para el proceso constituyente I: Plebiscito Ahora", en Claudio Fuentes y Alfredo Joignant (eds.), La Solución Constitucional. Plebiscitos, asambleas, congresos, sorteos y mecanismos híbridos. Catalonia, Santiago, pp. 237-51.

* Corral, Hernán (2015): "Proceso Constituyente y Argumento A Fortiori", disponible [en línea] https://corraltalciani.wordpress.com/2015/10/18/proceso-constituyente-yargumento-a-fortiori/ [última visita efectuada 23.11.2015].

* Correa Sutil, Sofía (2015): “Cambio Constitucional desde el Congreso Nacional”, en Fuentes, Claudio y Joignant, Alfredo (eds.), La Solución Constitucional. Plebiscitos, Asambleas, Congresos, Sorteos y Mecanismos Hibridos (Santiago, Catalonia).

* Kahn, Paul W. (2011): Political Theology. Four New Chapters on the Concept of Sovereignty. Columbia University Press, Nueva York.

* Kalyvas, Andreas (2005): "Popular Sovereignty, Democracy, and the Constituent Power", en Constellations, ( $\left.{ }^{\circ} 12\right)$, pp. 223-44.

* García, José y Verdugo, Sergio (2015): “Un Camino a la Constitución de 2020: Un Proceso Constituyente que Una y no Divida a los Chilenos", en Fuentes, Claudio y Joignant, Alfredo (eds.), La Solución Constitucional. Plebiscitos, Asambleas, Congresos, Sorteos y Mecanismos Híbridos (Santiago, Catalonia).

* Garretón, Manuel (2015): "Etapas y Mecanismos del Proceso Constituyente", en Fuentes, Claudio y Joignant, Alfredo (eds.), La Solución Constitucional. Plebiscitos, Asambleas, Congresos, Sorteos y Mecanismos Hibridos (Santiago, Catalonia).

* Henríquez, Miriam (2011): "El control de constitucionalidad de la reforma constitucional en el ordenamiento constitucional chileno", en Anuario de Derecho Público 2011, Universidad Diego Portales, pp. 461-477.

* Lindahl, Hans (2008): "Constituent Power and Reflexive Identity: Towards an Ontology of Collective Selfhood", en Martin Loughlin y Neil Walker (eds), The Paradox of Constitutionalism: Constituent Power and Constitutional Form. Oxford University Press, Oxford.

* Loughlin, Martin (2010): Foundations of Public Law. Oxford University Press, Oxford. 
* Nogueira, Humberto (2006): "Los límites del poder constituyente y el control de constitucionalidad de las reformas constitucionales en Chile", en Estudios Constitucionales, Año 4, N² 2, pp. 435-455.

* RiffoElgueta, Ernesto (2016): "Participación, plebiscito, y reemplazo constitucional: Consideraciones políticas y jurídicas", en Arce, Javiera y De la Fuente, Gloria (eds.) El derecho a participar: Contribuciones al debate sobre la deliberación ciudadana en la vida pública (Santiago, Ril Editores).

* Soto, Francisco (2015): "Propuesta para el Cambio Constitucional", en La Tercera, 14 de septiembre 2015.

* Szmulewicz, Esteban (2015): "Proceso Constituyente y Congreso Constituyente: Propuesta de Diseño Institucional para la Participación y la Deliberación”, en Fuentes, Claudio y Joignant, Alfredo (eds.), La Solución Constitucional. Plebiscitos, Asambleas, Congresos, Sorteos y Mecanismos Hibridos (Santiago, Catalonia).

* Torres, César (2007): De las aulas a las urnas: La Universidad del Rosario, la Séptima Papeleta y la Constituyente de 1991 (Bogotá, Editorial Universidad del Rosario).

* Urbinati, Nadia (2014): "Free Speech as the Citizen's Right", en Robert C. Post, Citizens Divided. Campaign Reform and the Constitution. Harvard University Press, Cambridge.

* Zapata, Patricio (2015): "La Constitución del Bicentenario. Once Tesis y Una Propuesta Concreta", en Fuentes, Claudio y Joignant, Alfredo (eds.), La Solución Constitucional. Plebiscitos, Asambleas, Congresos, Sorteos y Mecanismos Hibridos (Santiago, Catalonia).

* Zúñiga, Francisco (2006): "Control de constitucionalidad de la reforma constitucional", , en Estudios Constitucionales, Año 4, N 2, pp. 415-434.

(2015): "La Potestad Constituyente y la Nueva Constitución”, en Fuentes, Claudio y Joignant, Alfredo (eds.), La Solución Constitucional. Plebiscitos, Asambleas, Congresos, Sorteos y Mecanismos Hibridos (Santiago, Catalonia). 